\title{
Cigarette smoking among pregnant women in Poland
}

\author{
Cezary Wojtyła', Paulina Wojtyła-Buciora ${ }^{2,3}$ \\ 'First Department of Obstetrics and Gynaecology, Centre of Postrgraduate Medical Education, Wasaw, Poland \\ 2Department of Physiology, University of Medical Sciences, Poznan, Poland \\ 3Higher Vocational State School, Kalisz, Poland
}

\begin{abstract}
Introduction: Smoking is an extremely dangerous habit for pregnant women because, in addition to the negative health effects on reproductive functions, it also has a negative impact on the developing foetus. Despite the increasing awareness among pregnant women of the negative effects of tobacco smoking on foetal development and the functioning of the child, only a quarter of women quit smoking while being pregnant.

Material and methods: Analyses of the population of pregnant women in Poland were carried out using survey questionnaires within the framework of the Polish Pregnancy-related Assessment Monitoring System (Pol-PrAMS).

Results: Over $18 \%$ of women smoked cigarettes during the last three months preceding pregnancy. The percentage of women who smoked at least one cigarette in the first months of pregnancy was $6.8 \%$, while in the last trimester this figure was $7.7 \%$. The percentage of women smoking after childbirth was $3.6 \%$. In each successive year in which this study was conducted, the percentage of non-smoking women in the individual periods analysed was seen to rise. Each year, the highest percentages of women smoking cigarettes were those in the period before pregnancy.

Conclusions: It is necessary to conduct educational programs, aimed primarily at young women, to discourage them from smoking and to increase their awareness of the adverse effects of smoking during pregnancy.
\end{abstract}

KEY WORDS: smoking, pregnancy, maternal smoking.

ADDRESS FOR CORRESPONDENCE: Cezary Wojtyła, First Department of Obstetrics and Gynaecology, Centre of Postgraduate Medical Education, 231 Czerniakowska Street, 00-416 Warsaw, Poland, e-mail: czwo@op.pl

\section{INTRODUCTION}

Smoking is an extremely dangerous habit for pregnant women because, in addition to the negative health effects on reproductive functions, it also has a negative impact on the developing foetus. Studies show that tobacco smoking is a risk factor that may lead to infertility [1]. Tobacco smoking by pregnant women can increase the risk of miscarriage, low birthweight, intrauterine growth retardation of the foetus, ectopic pregnancy, and the development of other complications. It also increases the risk of sudden infant death syndrome, negatively affects the child's intellectual development, and increases the risk of the child becoming a smoker in the future $[1,2]$.

Despite the increasing awareness among pregnant women of the negative effects of tobacco smoking on foetal development and the functioning of the child, only a quarter of women quit smoking while being pregnant [1]. In the United States, the number of pregnant smokers declined over a 10 -year period from $18 \%$ in 1990 to $12 \%$ in 2001 [3]. However, among teenage mothers the spread of smoking increased slightly. In 1994, 16.7\% of teenage pregnant women smoked tobacco, whereas at the beginning of this century this percentage had risen to $17.5 \%$ [4]. In Poland, the prevalence of smoking among women aged 20-44 years is $31 \%$ [5]. Among the teenage population $11.82 \%$ of 15 -year-olds admit to smoking, and the figures systematically increase to $28.18 \%$ among 19-year-olds [6]. At present, Europe is seeing a decline in the consumption of tobacco by men, while its consumption by women is increasing [7]. It should be noted here 
that the most effective way to reduce the risk of adverse pregnancy outcomes is to stop smoking tobacco, so it is important to educate young women and future mothers about how to reduce the risk of possible complications.

\section{MATERIAL AND METHODS}

Analyses of the population of pregnant women in Poland were carried out using survey questionnaires within the framework of the Polish Pregnancy-related Assessment Monitoring System (Pol-PrAMS). The questionnaire was based on a survey used in the USA for the Pregnancy Risk Assessment Monitoring Survey (PRAMS) [8].

The research was conducted between 2010 and 2012 as a population study. It was conducted annually, in different months of the year, in order to obtain a representative test group. This was because it was assumed that the number of births may fluctuate seasonally. The study was conducted on a group of Polish women and their newborns, in all hospitals in Poland in which women following childbirth were staying along with their newborns.

The survey questionnaires were addressed to women convalescing postpartum in hospitals that had at least one of the following wards: Maternity, Gynaecology and Obstetrics, Rooming-in Maternity, Neonatal, or a Childbirth Room. The study was conducted on a nationwide basis. The purpose was to assess the health-related behaviour of pregnant women in Poland, such as their physical activity, diet and its supplements, smoking, and consumption of alcohol and psychoactive substances, as well as to assess the course of their pregnancies, and the birth and the condition of both newborns and mothers after childbirth.

The survey's questionnaire was divided into two parts. The first section contained information about the preg-

TABLE 1. Number and percentage of women smoking cigarettes and their amounts during pregnancy

\begin{tabular}{|l|c|c|}
\hline Active smoking & $N$ & $\%$ \\
\hline In the 3 months before pregnancy & 8578 & 100.0 \\
\hline None & 7022 & 81.9 \\
\hline $1-10$ & 1055 & 12.3 \\
\hline$>10$ & 501 & 5.8 \\
\hline In the first months of pregnancy & 8553 & 100.0 \\
\hline None & 7965 & 93.2 \\
\hline $1-10$ & 508 & 5.9 \\
\hline$>10$ & 80 & 0.9 \\
\hline In the last 3 months of pregnancy & 8595 & 100.0 \\
\hline None & 7936 & 92.3 \\
\hline $1-10$ & 577 & 6.7 \\
\hline$>10$ & 82 & 1.0 \\
\hline After childbirth & 8590 & 100.0 \\
\hline None & 8284 & 96.4 \\
\hline $1-10$ & 260 & 3.0 \\
\hline$>10$ & 46 & 0.6 \\
\hline
\end{tabular}

nant subjects, such as age, place of residence, education, marital status, social status, obstetric history (previous births, miscarriages, and any difficulties with becoming pregnant), and any behaviour by the mother before and during pregnancy constituting a health risk (smoking, alcohol consumption, drugs or psychoactive substances). The second section contained information about the childbirth, results of laboratory tests of the mother and child, and information about the health of the baby. The first part of the form was completed by mothers who, along with their newborn babies, remained in hospital after childbirth. The second section was completed by the specialised medical staff (doctor, nurse) responsible for taking care of the mother and newborn after childbirth, citing the subject's medical documentation.

The survey included questions about the number of cigarettes smoked in the following periods: during the three months preceding pregnancy, in the first months of pregnancy, in the last three months before childbirth, and at the present time, i.e. in the first days following childbirth.

In total, 9051 women with newborn babies qualified for inclusion in this analysis in 2010-2012. During the study period, the questionnaire was filled out by 8625 mothers, constituting 95.3\% who were thus analysed statistically. These were women who answered at least one of the survey questions. They represented $76.9 \%$ of the total number of women in obstetrics wards in Poland at that time.

Calculations were carried out by means of the statistics program SPSS PL version 12 and IBM SPSS Statistics version 22.

The methodology of this study is described in detail in a separate article [9].

\section{RESULTS}

Over $18 \%$ of women smoked cigarettes during the last three months preceding pregnancy, while $81.9 \%$ of women declared that they did not smoke during this period. The percentage of women who smoked at least one cigarette in the first months of pregnancy was $6.8 \%$, while in the last trimester this figure was $7.7 \%$. The percentage of women smoking after childbirth was $3.6 \%$. At these same times, the percentage of non-smoking women was $93.2 \%, 92.3 \%$, and $96.4 \%$, respectively. The number and percentage of women smoking cigarettes during pregnancy is shown in Table 1.

In each successive year in which this study was conducted, the percentage of non-smoking women in the individual periods analysed was seen to rise. Each year, the highest percentages of women smoking cigarettes were those in the period before pregnancy. In all three years analysed, there was an increase in the percentage of non-smoking women in the last trimester of pregnancy. The highest percentage of non-smoking women was observed in the period following childbirth. The percentage of non-smoking women in each year is shown in Table 2. 


\section{DISCUSSION}

Active smoking by pregnant women is considered to be the most important risk factor for adverse pregnancy outcomes, including low birthweight and preterm birth. The risk of complications depends on the number of cigarettes smoked a day. It has been noted that the harmful effect of smoking on the birthweight of newborns exists even in the case of a small number of cigarettes smoked per day [10]. Quitting smoking in early pregnancy also seems to reduce the risk of premature births and low birthweight [11-13]. The effects of smoking by pregnant women on foetal growth can vary depending on the duration and intensity of smoking. This is due to the fact that the growth and development of certain systems in the foetus differ in particular periods of pregnancy [14]. When during the most intense foetal development there occurs any unfavourable change in the foetal environment, this can cause its growth to be decreased or impaired. For example, the length of the foetus and the circumference of the head increase linearly during the second and most of the third trimester of pregnancy. However, the incline of the curve for foetal body weight increases sharply during the third trimester, especially after the $30^{\text {th }}$ week of pregnancy. If during these periods a woman smokes intensively, this may limit the growth of the foetus and the development of particular organs and systems $[15,16]$. Smoking also has further consequences both in infancy and in adult life. It negatively affects the development of cognitive functions [17-21], the functioning of the respiratory system in infancy and childhood [22, 23], and growth in children [24].

Our research shows that among the whole group of pregnant women surveyed, $18.1 \%$ smoked cigarettes before they were pregnant. In the first months of pregnancy, this percentage was $6.8 \%$, while in the last trimester $7.7 \%$ of pregnant mothers actively smoked cigarettes. It is highly probable that the last of the above groups are women who smoked throughout their pregnancy. For comparison, other Polish studies [25] show that the group of women smoking cigarettes throughout their pregnancy is $11.6 \%$, whereas only $8.6 \%$ smoked in the first four months of pregnancy. These studies indicate that $8 \%$ of women smoked between 1 and 10 cigarettes a day, and $2 \%$ of women smoked more than 10 cigarettes a day. 1.6\% of pregnant women smoked just occasionally (one cigarette per week or less). Jaddoe et al. noted that the percentage of pregnant women smoking in the last weeks of pregnancy is $17.2 \%$ [26]. A study conducted by Gacek indicates that there is a large difference in the prevalence of smoking during pregnancy, depending on the age of the future mother [27]. It follows that the percentage of pregnant women aged 18-30 years smoking during pregnancy is $34.4 \%$, while in the group of older pregnant women this figure is $9.9 \%$. The Euro-PERISTAT study makes it possible to compare the prevalence of tobacco smoking among future mothers in Poland and other European countries
TABLE 2. Percentage of non-smoking women before pregnancy, in the $3^{\text {rd }}$ trimester of pregnancy, and after childbirth in 2010, 2011, and 2012

\begin{tabular}{|l|c|c|c|}
\hline & $\begin{array}{c}\text { Before } \\
\text { pregnancy }\end{array}$ & $\begin{array}{c}\text { In the 3 } \\
\text { trimester }\end{array}$ & $\begin{array}{c}\text { After } \\
\text { childbirth }\end{array}$ \\
\hline 2010 & $78.3 \%$ & $88.6 \%$ & $93.8 \%$ \\
\hline 2011 & $82.9 \%$ & $93.9 \%$ & $97.6 \%$ \\
\hline 2012 & $84.5 \%$ & $94.6 \%$ & $98.0 \%$ \\
\hline
\end{tabular}

[28]. It shows that in 2010 the prevalence of smoking among Polish women before pregnancy was $24.6 \%$, while in the third trimester only $12.3 \%$ of women smoked.

Our own studies were based on questionnaires, the first part of which was filled out by women following childbirth. Such a circumstance may lead to the group of women smoking cigarettes to be underestimated. In developed countries, there is high public awareness of the harmful effects of smoking on health, and tobacco smoking during pregnancy is in most cases negatively assessed. This involves a risk that such a method of data collection is not fully reliable. Although the surveys were conducted anonymously, women could declare a lower number of cigarettes smoked than in actual fact, or even ignore the fact that they had smoked, thus qualifying to be included in the group of non-smokers during pregnancy. A more objective method of qualifying them for inclusion in the different groups would be to test them for cotinine concentrations in saliva or blood. West et al. investigated the prevalence of smoking by comparing the questionnaires completed by the subjects themselves with cotinine concentrations in their blood or saliva [29]. The authors observed significant differences in the results of the two methods. In Poland, the percentage of subjects tending to purposefully underestimate their smoking levels amounted to $6.0 \%$. In addition, studies by Wang et al. compared the results obtained from questionnaires filled in by pregnant women with test results for cotinine concentrations in the blood of those same subjects [15]. It turns out that where the methodology is based on measurement of cotinine concentrations in the mother's blood, the effect of the mother's smoking on foetal weight gain, growth, and head circumference is greater.

The above study indicates that slightly over $18 \%$ of women of reproductive age smoke cigarettes. At the same time, $7.7 \%$ smoke cigarettes throughout their pregnancy, exposing their child to an unfavourable environment in which to develop. Certainly, a positive observation is the decrease in successive years in the percentage of women smoking cigarettes.

\section{CONCLUSIONS}

It is necessary to conduct educational programs, aimed primarily at young women, to discourage them from smoking and to increase their awareness of the adverse effects of smoking during pregnancy. 


\section{DISCLOSURES}

Authors report no conflict of interest.

\section{References}

1. Centers for Disease Control and Prevention. Reproductive Effects. Surgeon General's Report - The Health Consequences of Smoking. Centers for Disease Control and Prevention, Atlanta 2004.

2. Cornelius MD, Leech SL, Goldschmidt L, et al. Prenatal tobacco exposure: is it a risk factor for early tobacco experimentation? Nicotine Tob Res 2000; 2: 45-52.

3. Guyer B, Freedman MA, Strobino DM, et al. Annual summary of vital statistics: trends in the health of Americans during the 20th century. Pediatrics 2000; 106: 1307-1317.

4. Martin JA, Hamilton BE, Ventura SJ, et al. Births: final data for 2001. Natl Vital Stat Rep 2002; 51: 1-102.

5. Zatoński W, Przewoźniak K, Sulkowska U, et al. Tobacco smoking in countries of the European Union. Ann Agric Environ Med 2012; 19: 181-192.

6. Wojtyła A, Goździewska M, Paprzycki P, et al. Tobacco-related Foetal Origin of Adult Diseases Hypothesis - population studies in Poland. Ann Agric Environ Med 2012; 19: 117-128.

7. Gilmore A, Pomerleau J, McKee M, et al. Prevalence of smoking in 8 countries of the former Soviet Union: results from the living conditions, lifestyles and health study. Am J Public Health 2004; 94: 2177-2187.

8. Center for Disease Control and Prevention. PRAMS. Available from: http://www.cdc.gov/prams (accessed: 20 December 2016).

9. Wojtyla C, Wojtyla-Buciora P. Polish Pregnancy-related Assessment Monitoring System (Pol-PrAMS): research on lifestyle health behaviour of Polish women during gestation - study design. J Health Inequal 2016; 2: 185-191.

10. Vardavas CI, Chatzi L, Patelarou E, et al. Smoking and smoking cessation during early pregnancy and its effect on adverse pregnancy outcomes and foetal growth. Eur J Pediatr 2010; 169: 741-748.

11. Lumley J, Chamberlain C, Dowswell T, et al. Interventions for promoting smoking cessation during pregnancy. Cochrane Database Syst Rev 2009; 3 :CD001055

12. McCowan LM, Dekker GA, Chan E, et al. Spontaneous preterm birth and small for gestational age infants in women who stop smoking early in pregnancy: prospective cohort study. BMJ 2009; 338: b1081.

13. Meyer S, Raisig A, Gortner L, et al. In utero tobacco exposure: the effects of heavy and very heavy smoking on the rate of SGA infants in the Federal State of Saarland, Germany. Eur J Obstet Gynecol Reprod Biol 2009; 146: 37-40.

14. Villar J, Belizan JM. The timing factor in the pathophysiology of the intrauterine growth retardation syndrome. Obstet Gynecol Surv 1982; 37: 499-506.

15. Wang X, Tager IB, Van Vunakis H, et al. Maternal smoking during pregnancy, urine cotinine concentrations, and birth outcomes. A prospective cohort study. Int J Epidemiol 1997; 26: 978-988.

16. Lieberman E, Gremy I, Lang JM, et al. Low birthweight at term and the timing of foetal exposure to maternal smoking. Am J Public Health 1994; 84: 1127-1131.

17. Fried PA, O'Connell CM, Watkinson B. 60- and 72-month follow-up of children prenatally exposed to marijuana, cigarettes, and alcohol: cognitive and language assessment. J Dev Behav Pediatr 1992; 13: 383-391.

18. Sexton M, Fox NL, Hebel JR. Prenatal exposure to tobacco: II. Effects on cognitive functioning at age three. Int J Epidemiol 1990; 19: 72-77.

19. Tong S, McMichael AJ. Maternal smoking and neuropsychological development in childhood: a review of the evidence. Dev Med Child Neurol 1992; 34: 191-197.

20. Olds DL, Henderson CR Jr, Tatelbaum R. Intellectual impairment in children of women who smoke cigarettes during pregnancy. Pediatrics 1994; 93: 221-227.

21. Weitzman M, Gortmaker S, Sobol A. Maternal smoking and behavior problems of children. Pediatrics 1992; 90: 342-349.

22. Hanrahan JP, Tager IB, Segal MR, et al. The effect of maternal smoking during pregnancy on early infant lung function. Am Rev Respir Dis 1992; 145: 1129-1135.

23. Wang X, Wypij D, Gold DR, et al. A longitudinal study of the effects of parental smoking on pulmonary function in children 6-18 years. Am J Respir Crit Care Med 1994; 149: 1420-1425.

24. Eskenazi B, Bergmann JJ. Passive and active maternal smoking during pregnancy, as measured by serum cotinine, and postnatal smoke exposure. I. Effects on physical growth at age 5 years. Am J Epidemiol 1995; 142 (9 Suppl): S10-18.

25. Wierzejska R, Jarosz M, Sawicki W, et al. Antyzdrowotne zachowania kobiet ciężarnych. Tytoń, alkohol, kofeina [Inappropriate health behaviour of pregnant women. Tobacco, alcohol, caffeine]. Żywienie Człowieka i Metabolizm 2011; 28: 84-98.

26. Jaddoe VW, Troe EJ, Hofman A, et al. Active and passive maternal smoking during pregnancy and the risks of low birthweight and preterm birth: the Generation R Study. Paediatr Perinat Epidemiol 2008; 22: 162-171.

27. Gacek M. Niektóre zachowania zdrowotne oraz wybrane wskaźniki stanu zdrowia grupy kobiet ciężarnych [Certain health behaviours and selected indicators of health status among pregnant women]. Probl Hig Epidemiol 2010; 91: 48-53.

28. Euro-Peristat project with SCPE and Eurocat. European Perinatal Health Report: the health of pregnant women and babies in Europe in 2010. Available from: http://www.europeristat.com/ images/European\%20Perinatal\%20Health\%20Report_2010. pdf (accessed: 23 December 2016).

29. West R, Zatonski W, Przewozniak K, et al. Can we trust national smoking prevalence figures? Discrepancies between biochemically assessed and self-reported smoking rates in three countries. Cancer Epidemiol Biomarkers Prev 2007; 16: 820-822.

\section{AUTHORS' CONTRIBUTIONS}

CW collected data and prepared the research concept of the publication. CW, PWB analysed data, wrote the article, revised the paper and finally approved it. 